\title{
pnmbalina
}

(8)

\section{Um passado mais-que-perfeito: o impacto do clássico na arquitectura britânica}

Autor(es): $\quad$ Botto, Maria Isabel Donas

Publicado por: Imprensa da Universidade de Coimbra

URL

persistente: URI:http://hdl.handle.net/10316.2/32816

DOI: $\quad$ DOI:http://dx.doi.org/10.14195/978-989-26-0236-3_11

Accessed : $\quad$ 26-Apr-2023 15:41:25

A navegação consulta e descarregamento dos títulos inseridos nas Bibliotecas Digitais UC Digitalis, UC Pombalina e UC Impactum, pressupõem a aceitação plena e sem reservas dos Termos e Condições de Uso destas Bibliotecas Digitais, disponíveis em https://digitalis.uc.pt/pt-pt/termos.

Conforme exposto nos referidos Termos e Condições de Uso, o descarregamento de títulos de acesso restrito requer uma licença válida de autorização devendo o utilizador aceder ao(s) documento(s) a partir de um endereço de IP da instituição detentora da supramencionada licença.

Ao utilizador é apenas permitido o descarregamento para uso pessoal, pelo que o emprego do(s) título(s) descarregado(s) para outro fim, designadamente comercial, carece de autorização do respetivo autor ou editor da obra.

Na medida em que todas as obras da UC Digitalis se encontram protegidas pelo Código do Direito de Autor e Direitos Conexos e demais legislação aplicável, toda a cópia, parcial ou total, deste documento, nos casos em que é legalmente admitida, deverá conter ou fazer-se acompanhar por este aviso. 
Carmen Soares

Maria do Céu Fialho

María Consuelo Alvarez Morán

Rosa María Iglesias Montiel

Coordenação

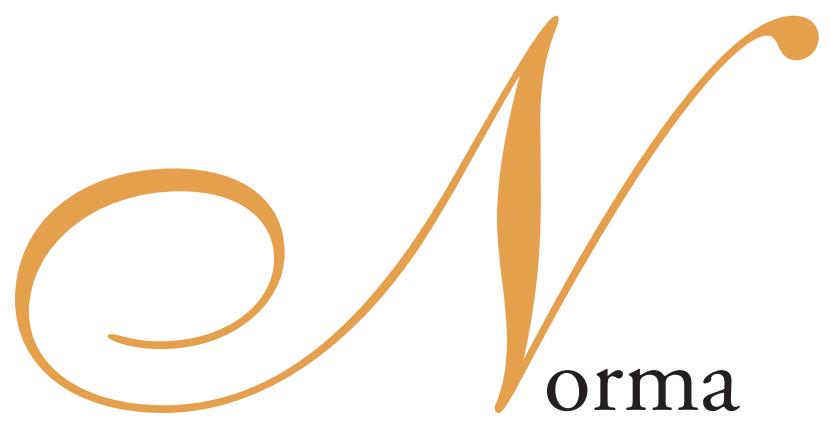

\& Transgressão

II

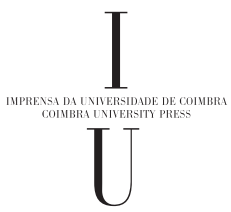




\author{
Carmen Soares \\ Maria do Céu Fialho \\ María Consuelo Alvarez Morán \\ Rosa María Iglesias Montiel \\ Coordenação
}

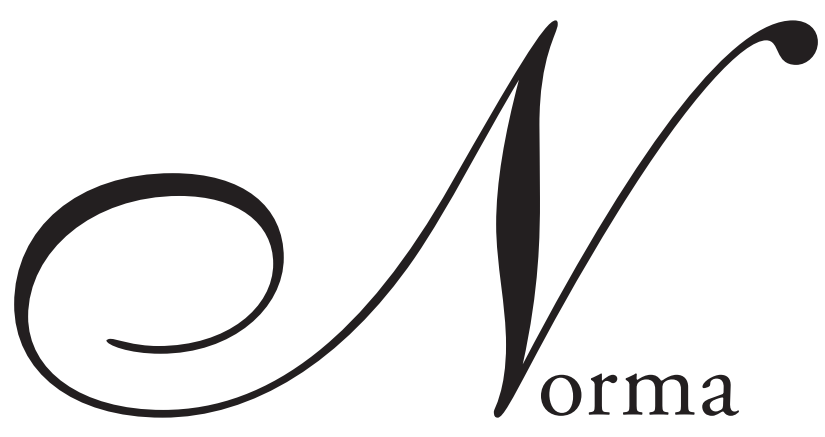

\& Transgressão

II

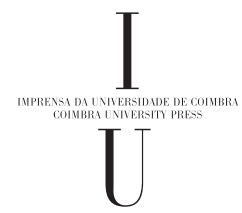




\title{
COORDENAÇÃo EDITORIAL
}

Imprensa da Universidade de Coimbra

Email: imprensauc@ci.uc.pt

URL: http://www.uc.pt/imprensa_uc

Vendas Online: http://www.livrariadaimprensa.com

\author{
CONCEPÇÃO GRÁFICA \\ António Barros \\ INFOGRAFIA \\ Carlos Costa \\ Imprensa da Universidade de Coimbra
}

EXECUÇÃO GRÁFICA

Europress

ISBN

978-989-26-0105-2

Depósito LEgal

OBRA PUBlicada COM O APOIO de:

Centro de Estudos Clássicos e Humanísticos

Faculdade de Letras da Universidade de Coimbra

FCT Fundação para a Ciência e a Tecnologia

MINISTÉrio DA CIÊNCCA, TECNOLOGIA E ENSINO SUPERTOR Porugal

Programa Operacional Ciência e Inovação 2010 


\section{CAPítulo II}

Os ClásSicos e a SUA RECEPÇÃo: CONTRIBUTOS PARA A (DES)CONSTRUÇÃO DE IDENTIDADES CULTURAIS 
2.3. Arquitectura 


\title{
UM PASSADO MAIS-QUE-PERFEITO: \\ O IMPACTO DO CLÁSSICO NA ARQUITECTURA BRITÂNICA
}

\begin{abstract}
Resumo
O "império do bom gosto" é uma expressão que, na sua versão inglesa "the rule of taste" -, tem sido largamente utlizada para descrever o domínio de parâmetros clássicos que marcou o desenvolvimento das artes, e em particular da arquitectura inglesa, durante perto de dois séculos (entre os meados do século XVII e o princípio do século XIX). O grande número de casas senhoriais construídas durante esse período constitui a expressão mais eloquente deste classicismo. A "country house" foi desde então elevada a ícone do (bom) gosto, da tradição e da identidade nacionais.

A identificação do classicismo com a tradição arquitectónica britânica não foi, contudo, pacífica, tendo-se verificado, desde o princípio do século XIX e até aos nossos dias, um persistente e nem sempre bem sucedido desafio dos parâmetros clássicos. Neste ensaio parte-se do comentário do processo de implantação da estética clássica, cujo carácter normativo foi consagrado no paladianismo e simbolizado na mansão senhorial jorgiana. O objectivo prende-se não apenas com a apreciação do alcance de algumas das propostas estéticas mais desafiadoras do "gosto inglês", mas também com o debate que continua a marcar a arquitectura britânica, entre o que uns chamam de "tradicionalismo" e outros de "classicismo", por um lado, e o modernismo, por outro.
\end{abstract}


Lodged deep in the subconscious of every Briton lies a complete familiarity with columns and cornices, arches and astragals.

Robert Adam $^{1}$

\section{A divulgação do classicismo}

A epígrafe deste artigo deve ser apreciada com alguma ironia: estas palavras de um bem sucedido arquitecto britânico contemporâneo - que por acaso partilha o nome com um reputado arquitecto neoclássico britânico do século XVIII ${ }^{2}$ - traduzem apenas a opinião do seu autor. Na sua formulação pouco feliz, esta epígrafe não deixa, todavia, de apontar para um tema central desta minha comunicação: a associação entre uma suposta identidade britânica e o "clássico".3

O "novo estilo" do Renascimento chegou tarde a Inglaterra. Não obstante o indiscutível brilho literário e artístico do reinado de Isabel I (1558-1603), é no princípio do século XVII que se constata o impacto de um crescente interesse pela arquitectura da Antiguidade Romana em Inglaterra, na obra do arquitecto inglês Inigo Jones. ${ }^{4}$ Acabado de regressar de uma longa viagem pela Itália onde estudara atentamente a arquitectura renascentista, bem

1 Robert Adam, apud Whiteley, 1992: 205.

Robert Adam é um empenhado defensor do "clássico" na arquitectura contemporânea. Na página web do seu gabinete de arquitectura, "ADAM Architecture", a apresentação inicia-se com a seguinte afirmação: "ADAM Architecture has an international reputation in classical and traditional architecture and design": http://www.adamarchitecture.com/people.htm (meu itálico).

2 Robert Adam, influente arquitecto e designer escocês (1728-1792), um dos expoentes da estética clássica setecentista.

3 Neste artigo adopta-se a interpretação do termo "clássico" apresentada por Summerson, em The Classical Language of Architecture. Realçando a complexidade do termo, Summerson salienta, para além do sentido óbvio, "[a] classical building is one whose decorative elements derive directly or indirectly from the architectural vocabulary of the ancient world - the 'classical' world as it is often called - [which] are easily recognizable...", a relevância dos conceitos de "proporção" e "harmonia" (Summerson, 1991: 8).

${ }^{4}$ Inigo Jones (1573-1652) é o mais importante arquitecto inglês da Renascença. Profundo conhecedor da arquitectura renascentista italiana, através das viagens que realizou por toda a Itália - tendo inclusivamente privado com alguns dos discípulos de Andrea Palladio - foi o introdutor do novo estilo em Inglaterra. 
como algumas das ruínas romanas, Jones projectou e supervisionou a construção, em Inglaterra, do primeiro edifício que se pode identificar como plenamente "clássico", na medida em que foi construído de acordo com as regras postuladas por Andrea Palladio e outros divulgadores renascentistas deste tipo de arquitectura: a Casa da Rainha ("Queen's House", 1516), oferecida por Jaime I à sua mulher, a Rainha Ana (Fig. 1). ${ }^{5}$

Este palacete obteve considerável impacto, à altura da sua construção, pelo seu contraste com a arquitectura dominante: o poder e a riqueza da aristocracia isabelina e jacobina, nomeadamente a nova nobreza associada à causa protestante, espelhavam-se num número considerável de palacetes e casas senhoriais, mas todos estes edifícios se mantiveram globalmente fieis ao gótico tardio inglês - mesmo que algumas colunas fossem fazendo a sua aparição, numa tímida manifestação de conhecimento do que de mais moderno se ia fazendo na distante Itália. Hardwick Hall (1597), em Derbyshire, é um dos exemplos mais sofisticados da arquitectura isabelina (Fig. 2).

A Casa da Rainha era, portanto, um objecto estranho - "a curious device", na expressão de um contemporâneo (apud A. Gomme 1992: 65), patenteando uma estética de um rigor e contenção que os contemporâneos entenderam, compreensivelmente, como estrangeira. Infelizmente, Inigo Jones, arquitecto da corte de Jaime I e Carlos I, deixou uma obra arquitectónica muito parca, onde releva a também notável Banqueting House (Fig. 3). Este edifício plenamente renascentista destacava-se, em 1622, do conjunto de velhos edifícos medievais góticos que constituiam o palácio real de Whitehall, destaque acentuado pela magnífica pintura do tecto da autoria de Rubens, concluída em 1634.

Esperar-se-ia, portanto, que a arquitectura inglesa iniciasse um novo capítulo de florescimento artístico, centrado nesse novo estilo. O classicismo entendido como uma arquitectura guiada pelos modelos da Antiguidade Greco-Latina (embora inicialmente filtrados pelos arquitectos da Renascença

\footnotetext{
5 Andrea Palladio (1508-80), reputado arquitecto da Renascença italiana tardia, autor do influente tratado I Quatro Libri di Architettura, publicado em 1570.
} 
italiana) e pautada por um escrupuloso respeito pelas ordens - era conhecido e admirado por uma elite aristocrática muito restrita, mas começava a despertar o interesse dos estudiosos, como o comprovam os tratados publicados no início do século XVII. Em 1624 Henry Wotton (1568-1639) publicou The Elements of Architecture, o primeiro tratado de fundo de um autor inglês sobre a teoria vitruviana de arquitectura.

A divulgação da nova estética acabou, no entanto, por ser dificultada pela evolução política do país, pelo que o seu impacto só foi plenamente sentido algumas décadas depois.

\section{A ideologia do clássico}

A segunda metade do século XVII foi um período muito conturbado da história da Inglaterra: no espaço de 60 anos (entre 1640 e 1700), o país passou por duas guerras civis (anos 40), o regicídio e a implantação da república (1649), a restauração da monarquia (1660), um surto devastador de peste e o Grande Incêndio de Londres (anos 60), a deposição de um monarca e subsequente Revolução palaciana (1688) que destruiu, para sempre, as hipóteses do absolutismo nas Ilhas Britânicas. ${ }^{6}$ Significa isto que, no início de setecentos, a Inglaterra, já unificada com a Escócia (1707), enceta um fértil percurso de desenvolvimento e enriquecimento - estruturado sobre um império colonial que se ia consolidando - resolvidas que estão as principais questões de natureza político-constitucional. Iniciam-se, assim,

\footnotetext{
${ }^{6}$ A chamada Revolução Gloriosa, em 1688, instituiu os princípios da monarquia constitucional - sem uma constituição escrita, é certo, mas com uma Carta dos Direitos que, entre outros aspectos, identifica e ilegaliza as prerrogativas reais mais significativas e institui a supremacia do Parlamento e a independência dos tribunais. Simultaneamente, foram promulgadas leis que instituiram o Habeas Corpus, a tolerância religiosa e a abolição do Licenciamento Prévio dos Textos.
} 
os anos de domínio da dinastia hanoveriana, o reinado dos Jorges (1715-1830), e o que para muitos continua a ser o período áureo da arquitectura britânica. ${ }^{7}$

Em 1729, Lord Burlington (1694-1753), um dos mais importantes representantes da aristocracia Whig, a facção política associada e em grande parte responsável pelo combate ao absolutismo real em Inglaterra, viu concluída a sua casa, Chiswick House, um projecto em parceria com o arquitecto seu protegido e amigo, William Kent. A casa apresenta grandes semelhanças com La Rotonda, construída em 1591, em plena Renascença, e projectada por Andrea Palladio (Fig. 4 e 5: Andrea Palladio, La Rotonda, 1591; William Kent e Lord Burlington, Chiswick House, 1729)

Chiswick House poderá ter parecido tão estranha (estrangeira) aos olhos dos contemporâneos de Lord Burlington como a Queen's House aos dos compatriotas de Inigo Jones, um século antes: equilibrada, de uma geometria rigorosa, austera e imponente, destaca-se incongruentemente no bucólico campo que nos habituámos a identificar como "inglês". Mas o simples facto de a primeira destas casas ser uma encomenda real e a segunda, uma residência privada indicia uma realidade sociocultural substancialmente diversa: a aristocracia domina agora o patrocínio das artes, e em particular da arquitectura. O hábito do "Grand Tour" divulga-se entre a aristocracia desde o final de seiscentos, familiarizando a elite britânica com as ruínas da Antiguidade e os monumentos da Renascença, e promovendo o gosto pelo coleccionismo. ${ }^{8}$ Para alguns destes nobres, no entanto (é o caso de Burlington), o interesse pela arte leva-os a procurar aumentar os seus conhecimentos nessa área e até mesmo a lançar a mão a projectos de edifícios.

\footnotetext{
7 Não se julgue, porém, que a arquitectura não floresceu até ao final do século; de facto, à excepção das décadas de 40-50, devastadoras para a maioria das artes plásticas, em particular a arquitectura e a escultura, a construção naturalmente avançou. O período que decorre entre o final da década de 60 e os anos 20 do século XVIII foi dominado por um dos grandes arquitectos britânicos - Sir Christopher Wren, autor da Catedral de S. Paulo e dos planos de reconstrução da cidade de Londres, após o Grande Incêndio de 1666. No entanto, o desenvolvimento artístico desse período controverso não se enquadra no âmbito deste artigo. Sobre esse tema, vide, entre outra bibliografia, A. Gomme, op.cit., e Maria Isabel da Cunha Donas Botto Ribeiro, "Arquitectura e Sociedade em Inglaterra: 1660-1714". Coimbra, 1998.

8 Sobre o Grand Tour, vide Andrew Wilson and Ilaria Bignamini (eds) Grand Tour: The Lure of Italy in the Eighteenth Century. London: Tate Gallery Publishing, 1996.
} 
Na verdade, a motivação de Burlington não era inteiramente pessoal: este influente nobre tinha uma agenda política que passava por encontrar uma expressão artística para o modelo sociopolítico inglês (ou britânico, a partir do Act of Union, em 1707, lei que consagra a união da Escócia a Inglaterra e Gales). O objectivo era criar um estilo que se impusesse como alternativa ao que se entendia como a perniciosa influência francesa, por um lado, e a estética barroca genericamente associada à Igreja Católica Romana, por outro; o estilo paladiano seria, assim, a expressão dos valores consagrados na revolução de 1688 e definitivamente alicerçados com a subida ao trono, em 1714, do rei Jorge I $^{9}$ - valores que os ideólogos do regime apresentavam como a liberdade e a tolerância, no respeito pela lei, pela ordem instituída e pela tradição.

Como comenta B. Arciszewska, após o difícil período de transição de poder, as primeiras décadas do século XVIII iniciam uma época de "imposed order",

when the desire for social harmony, conformity and politeness, kept the divergent political interests and conflicting social agendas in balance. Classicism was the perfect visualization of these ideals of order, restraint and control, and classical architecture in particular became the epitome of the new Britain. (...) The Palladian revival indeed became the perfect idiom of political conformity, rationalizing and celebrating the Hanoverian ascendancy as the rightful succession to the early Stuart monarchy, while at the same time accommodating the aspiration of Britain's elites." 10

O paladianismo domina a arquitectura jorgiana, praticamente incontestado, não obstante o seu rigor programático, explicitado na publicação, entre 1715 e 1725, dos 3 volumes do Vitruvius Britannicus, considerado o manifesto

9 Jorge I, Eleitor de Hanover, com uma muito remota ligação de parentesco à dinastia Stuart, foi convidado a ocupar o trono da Grâ-Bretanha para evitar a sucessão (legítima) católica.

10 B. Arciszewska 2004: 19. Um documento que ilustra claramente essa estratégia de legitimação do poder Whig da nova Grã-Bretanha é a "Letter Concerning the Art, or Science of Design", do amigo de Burlington, Anthony Ashley Cooper, Conde de Shaftesbury, escrita em 1712 e publicada mais tarde. 
fundador do paladianismo inglês. Tal como o seu título, o subtítulo desta obra seminal - "The British Architect" - constitui uma pista importante para compreender as razões do sucesso na implantação deste estilo: o objectivo do seu autor, Colen Campbell (1676-1729), um dos arquitectos amigos e protegidos de Lord Burlington, era chamar a atenção para a prática do arquitecto britânico, oferecendo, na riqueza das suas ilustrações, a obra de Palladio como o modelo para a arquitectura britânica, sem deixar, todavia, de recordar e recuperar o magnífico exemplo (nacional) de Inigo Jones, entretanto esquecido. O sucesso foi indiscutível:

\footnotetext{
Vitruvius Britannicus, the publication of which was strung out over almost a century, became the most important source of information about English architecture for the continent of Europe and for America. The Palladianism from which Campbell took his inspiration had the success it did because, at that moment, he was able to raise a style promoted by a small group of fellow-Palladians to the state of an English national style. (Kruft, 1994: 238)
}

Nas décadas seguintes, largas centenas de casas senhoriais continuarão a surgir por todo o país, rodeadas, tal como a daquele nobre, de belíssimos parques e jardins. O facto de esta tendência não se circunscrever à poderosa elite Whig evidencia o crescimento económico e a prosperidade do país, mas também o sucesso obtido na divulgação desta estética: o paladianismo penetrou fundo no activo mundo da construção jorgiano, difundindo os princípios da arquitectura clássica, seja pela publicação em tradução inglesa dos tratados mais importantes da Renascença italiana (alvo de sucessivas reedições), procurados pelos arquitectos mais conceituados e pelos seus clientes, seja pelo crescente número de manuais de arquitectura ("pattern books") que os arquitectos da provincía e os construtores, em geral, se habituaram a consultar.

Com efeito, se Chiswick House parece estrangeirada, o mesmo não se pode dizer de centenas de casas senhoriais elegantes, sóbrias mas sem o rigor programático da casa de Lord Burlington e de alguns dos seus 
"correligionários" - as country bouses da aristocracia fundiária e, à medida que o século se desenrola, da fidalguia rural abastada. Por outro lado, é de realçar a difusão deste classicismo numa sociedade que se vai gradualmente urbanizando, pelo que as casas de cidade de uma classe média e média-alta cada vez mais prósperas e desejosas de reconhecimento social representam uma fatia importante da construção. São incontáveis os exemplos de mansões rurais e casas de cidade jorgianas que povoam as cidades de província inglesas: individuais, geminadas ou em banda, casas sóbrias, elegantes, de tijolo vermelho e largas janelas brancas, de guilhotina, ou, mais solenes, todas brancas ou de pedra. Toda esta construção demonstra como esse sucesso da arquitectura (genericamente designada por) jorgiana resulta da endogeneização do paladianismo, processada ao longo de mais de um século, durante o qual o seu carácter normativo nunca foi eficazmente posto em causa - não significando isto que não tenha sido capaz de incorporar algum eclectismo e de, como atestam estas casas, alguma recriação. A questão continua, aliás, a ser debatida por críticos e historiadores da arquitectura britânica: alguns, como Jules Lubbock, autor do excelente The Tyranny of Taste, realçam que, dada a liberdade de opinião e relativa liberdade de mercado da Grã-Bretanha setecentista, nunca deixou de se manifestar alguma dissidência política e estética (J. Lubbock, 1995: 217), enquanto outros, como James Stevens Curl, em The Oxford Dictionary of Architecture and Landscape Architecture, argumentam que

As the high priest of English Palladianism, Burlington not only designed exemplary buildings but promoted the interest of architects sympathetic to the cause and encouraged publications that established the architectural vocabulary and language that were to dominate (even tyrannize) taste for most of the century. (J. S. Curl, 2006: 552) (meu itálico)

Preferencialmente simbolizada pela "country house", a bela mansão rodeada de apetecíveis relvados e majestosas árvores, ou, numa escala mais modesta, com um encantador jardim "inglês", irregular e pitoresco, a arquitectura jorgiana transformou-se no símbolo mais reconhecível de uma 
era de ouro que a historiografia inglesa do século xx consagrou em obras como The Rule of Taste ${ }^{11}$ - e que a florescente indústria do turismo (tal como a BBC) explora há várias décadas, com crescente sofisticação, e correspondentes lucros. ${ }^{12}$

Na Grã-Bretanha oitocentista, industrial, burguesa e predominantemente urbana, porém, já seria de esperar uma reacção forte à hegemonia da estética clássica. A arquitectura, a mais política das artes, não pode deixar de reflectir as grandes transformações sociais, bruscas, umas, mais graduais, outras. A partir dos anos 30 do século XIX, a sociedade britânica vai experimentar um confronto entre duas estéticas: o neoclássico, vulgarmente designado por"Greek revival” na Grâ-Bretanha oitocentista, e esse outro revivalismo que, no âmbito do movimento romântico, assolou também a Europa de oitocentos - o neogótico. Pelos contornos que assumiu e o grau de visibilidade alcançado, este foi um dos grandes debates culturais da primeira parte do século XIX, conhecido por "Batalha dos Estilos".

Neste confronto entre dois tipos de revivalismo, um inspirado na arquitectura medieval, outro, na da antiguidade, destaca-se John Ruskin (1819-1900), reputado crítico de arte e crítico social dos meados do século XIX. Não sendo o único, nem sequer o primeiro a fazê-lo, Ruskin sustenta e procura comprovar não apenas a adequabilidade do gótico à sociedade e cultura britânicas oitocentistas, decorrente da sua versatilidade, mas também e sobretudo a alegada superioridade moral do estilo, atribuindo a responsabilidade pelo estado da arquitectura das primeiras décadas de oitocentos a dois séculos de hegemonia clássica. A citação que se segue é uma expressão eloquente da sua condenação do classicismo:

The whole mass of the architecture, founded on Greek and Roman models $\ldots$ is utterly devoid of all life, virtue, honourableness, or power of doing

\footnotetext{
11 John Steegmann, The Rule of Taste from George I to George IV. London: Macmillan, 1936 - reeditada em 1968.

${ }^{12}$ Um exemplo recente é proporcionado pela edição em DVD do filme Pride and Prejudice, baseado no romance homólogo de Jane Austen (1813). Filmado em algumas emblemáticas casas senhoriais inglesas, inclui um documentário de divulgação destas residências históricas.
} 
good. It is base, unnatural, unfruitful, unenjoyable, and impious. Pagan in its origin, proud and unholy in its revival, paralysed in its old age. (...) An architecture invented ... to make plagiarists of its architects, slaves of its workmen, and sybarites of its inhabitants; an architecture in which intellect is idle, invention impossible, but in which all luxury is gratified, and all insolence fortified. (Ruskin, 1906: 192-3)

Na sua óbvia violência - excessiva mesmo no contexto da retórica hiperbólica de Ruskin - esta crítica ilustra adequadamente o grau do envolvimento do autor nessa questão, tão relevante para a geração dos meados do século, da escolha de um estilo para o século XIX. Para Ruskin, não se trata de fomentar a transgressão ou propor a infração de um cânone demasiado restritivo; trata-se de o refutar liminarmente - de o erradicar. A diatribe supracitada denuncia o que, na visão do autor, é o elitismo da estética clássica, o normativismo que atrofia a criatividade humana. Este é, de resto, o tema do capítulo $\mathrm{V}$ de The Stones of Venice, obra escrita em defesa do estilo gótico, estruturada num conhecimento profundo da arquitectura veneziana. A denúncia do normativismo clássico é apresentada, neste texto, como um grito de libertação:

Whatever has any connection with the five orders, or any one of the orders - whatever is Doric, or Ionic, or Tuscan, or Corinthian, or Composite, or in any way Grecized or Romanized; whatever betrays the smallest respect for Vitruvian laws, or conforming with Palladian work - that we are to endure no more. (ibidem, 193)

Ruskin partilhava da convicção de muitos outros defensores do gótico de que, enquanto prática arquitectónica desenvolvida ao longo de muitos séculos, por toda a Europa, nas suas múltiplas variantes, expressões e técnicas de construção, o gótico era o único estilo que se poderia considerar como um genuíno vernáculo no século XIX: um estilo capaz de se adaptar, de se transformar e até de gradualmente evoluir para um novo estilo. 
Numa campanha com ocasionais tonalidades de uma cruzada, o autor apresenta-se como paladino do gótico, defendendo-o não apenas como um estilo adaptável, elástico, informal e orgânico, mas também como expressivo e acessível — isto é, compreensível, "legível" por todos (por outras palavras, não é preciso ler tratados para o compreender). Nesta sua adaptabilidade e maleabilidade, o gótico seria, assim, um estilo também mais adequado a uma sociedade e uma época dominada, de uma forma sentida por muitos como assustadora, pelo crescimento das massas urbanas.

Se na batalha de estilos oitocentista - pautada por episódios de alguma crispação, o mais notável dos quais concerne a construção do emblemático Palácio de Whitehall, sede do então Ministério dos Negócios Estrangeiros ${ }^{13}$ - o gótico saiu vencedor, tal facto não levou à desejada evolução da arquitectura britânicas para um novo estilo nacional. Ou seja, a libertação da arquitectura britânica do que Ruskin e os seus correligionários entendiam como o jugo do normativismo clássico não abriu asas à criatividade nacional e não levou à criação de um estilo "genuíno", nacional, reflexo dos "valores britânicos": a Grã-Bretanha continuou estilisticamente presa ao passado, fosse ele gótico ou clássico. A sociedade vitoriana, próspera e dinâmica, foi palco de um pujante crescimento urbanístico cujas marcas são ainda hoje claramente visíveis de Norte a Sul do país. A construção pública e privada, civil e religiosa, atestam a riqueza e o vigor do neogótico vitoriano (a par de outros revivalismos), assim como de algumas manifestações interessantes de eclectismo mais para o fim do século. ${ }^{14}$ No entanto, o dealbar do século xx pouco mais trouxe do que a continuação da construção vitoriana.

13 Para uma descrição com algum humor deste episódio da Batalha dos Estilos, vide Nikolaus Pevsner, Pioneers of Modern Design, from William Morris to Walter Gropius. London: Penguin, 1991 [1936], pp. 12-20.

14 A Câmara Municipal de Manchester (1877, arquitecto Alfred Waterhouse) e St. George's Hall (1854, arquitecto Harvey L. Elmes), em Liverpool, dois edifícios públicos de grande envergadura, respectivamente em estilo neogótico e neoclássico, são dois exemplos contrastantes do orgulho cívico da burguesia industrial vitoriana. 


\section{Depois do modernismo}

Excepção feita a alguns edifícios isolados nas décadas de 20 e 30, a Grã-Bretanha só aderiu à nova estética do século xx entre os anos 50 e 70, durante os quais a conjugação da necessidade de muita construção de habitação, nomeadamente bairros sociais, e a centralização das obras públicas por via do esforço de reconstrução do pós-guerra e do período de forte desenvolvimento económico que se lhe seguiu, levaram à divulgação da construção em altura e em cimento armado.

Contudo, também neste período e neste âmbito, o resultado não foi assinalável. Se as obras de maior envergadura, obras de estado ou grandes empreendimentos públicos urbanos, da responsabilidade das autoridades regionais, seguiam as tendências gerais da construção moderna internacional, para a maioria da população - alojada em subúrbios que, nas suas diferentes localizações, assinalavam os diferentes níveis sociais - a preferência continuou a recair sobre variantes do "vernáculo", com particular destaque para o falso Tudor (em inglês, "mock Tudor"), onde predominam pormenores de inspiração gótica, como os telhados muito inclinados, as empenas e as chaminés trabalhadas, entre vários outros elementos decorativos. Por outro lado, as experiências feitas com a construção em altura em bairros sociais - que não foram muitas, mas se concentraram nessas décadas entre os anos 50 e 70 foram mal sucedidas, não tanto por falta de valor dos seus projectos, mas por falta de verbas na própria edificação e, por maioria de razões, na sua manutenção. Ou seja, se no século XIX a libertação dos parâmetros clássicos não levou à criação de um novo estilo, mas antes a um eclectismo globalmente alimentado por incursões no passado, também o importado Estilo Internacional do século xx, mal acolhido, não frutificou na Grã-Bretanha, acentuando até a situação depressiva que marcou a economia dos anos 70 e princípio de 80 .

Nas últimas décadas do século passado assistiu-se, primeiro nos EUA e depois na Europa, à divulgação da arquitectura dita pós-moderna, apresentada como uma arquitectura mais liberta e solta, ecléctica, provocantemente transgressora da norma modernista e segura da legitimidade das incursões 
pelo passado em busca de inspiração. Num país como a Grã-Bretanha, com uma relação incómoda com o modernismo e uma forte herança cultural, o pós-modernismo criou, assim, a oportunidade para, no âmbito da arquitectura e do urbanismo, debater e repensar a relação com o passado, bem como a relevância da herança cultural como geradora de continuidades.

Na verdade (e independentemente da qualidade arquitectónica, que não está aqui em análise), o mundo da arquitectura britânica recuperou uma efervescência que não se sentia desde os meados do século XIX - durante a referida Batalha dos Estilos. Nas últimas décadas do século xx e já no advento do novo milénio assiste-se a um aceso debate sobre os caminhos a adoptar pela arquitectura britânica contemporânea.

O confronto foi despoletado em 1984 por um discurso proferido pelo Príncipe Carlos, na sede do RIBA ("Royal Institute of British Architects, a entidade reguladora da profissão, correspondente à Ordem dos Arquitectos em Portugal). Neste discurso o Príncipe criticava severamente a veia modernista que, em seu entender, prevalecia na arquitectura britânica contemporânea, dominada pelo betão, metal e vidro (um tipo de arquitectura genericamente designada por "High Tech"); lamentava em particular que, entre outros "atentados" à capital britânica, o projecto da nova ala da National Gallery, em vez de dar continuidade à "elegante fachada" do edifício, mantendo o "conceito de colunas e cúpulas", o fosse desfigurar por completo; e terminava com a comparação da nova construção a uma "monstruosa pústula na bela face de uma amiga muito querida". ${ }^{15}$

Apelando a uma recuperação dos valores "tradicionais" e "humanos" na arquitectura, durante os anos 90 o príncipe envolveu-se numa campanha de divulgação desses valores, que se manifestou, entre muitas outras acções, na criação de uma fundação - "The Prince's Foundation for the Built Environment" - vocacionada para o fomento de uma arquitectura indistintamente descrita

\footnotetext{
15 (meu itálico) O discurso pode ser consultado na página web do Princípe de Gales: The Prince of Wales. Speeches and articles:

http://www.princeofwales.gov.uk/speechesandarticles/a_speech_by_hrh_the_prince_of_ wales_at_the_150th_anniversary_1876801621.html
} 
como tradicional e, sobretudo nos últimos anos, sustentável, procurando demonstrar uma ligação lógica entre estas duas características. ${ }^{16}$ Este neotradicionalismo acabou inevitavelmente por entroncar num movimento idêntico de origem norte-americana, o "New Urbanism", o qual, como o nome indica, propunha um novo tipo de urbanismo - centrado numa visão diferente do conceito de comunidade urbana, mais consentâneo com os valores tradicionais locais e uma arquitectura "à escala humana" - e que, quer nas suas propostas teóricas, quer nas opções estilísticas dos seus praticantes, pressupõe uma associação entre o tradicionalismo e o "classicismo". ${ }^{17}$

Um número significativo de arquitectos - americanos, sobretudo, mas também alguns britânicos (e ainda de outros países da Europa, embora no continente o movimento não tenha atingido grande expressão) - identificamse com este ideário, apoiando e aclamando a reabilitação do tradicionalismo, numa reacção por vezes virulenta ao que genericamente se designa por "modernismo" (metendo num mesmo saco a construção em altura, Le Corbusier e seguidores e o "High Tech", entre outras tendências). É significativo que o movimento tenha encontrado algum eco na historiografia britânica, reintegrando este tema no debate sobre a identidade nacional. Nos anos 90, alguns historiadores de arte manifestam publicamente o seu desagrado relativamente à aplicação dos preconceitos por vezes classificados "europeus" - dominados pelos parâmetros do modernismo - na avaliação dos sucessos e insucessos da arquitectura e pintura britânicas do século XIX e $\mathrm{xx}^{18}$

16 "Na página de apresentação da Fundação, lê-se; "The Prince's Foundation for the Built Environment is a charity which exists to improve the quality of people's lives by teaching and practising timeless and ecological ways of planning, designing and building" (http://www. princes-foundation.org/)

17 Não cabe neste artigo uma análise detalhada das características e objectivos do New Urbanism. Sobre o assunto, vide Peter Katz (1994), New Urbanism: Towards an Architecture of Community. New York: McGraw-Hill Professional; para uma visão crítica, David Harvey, "The New Urbanism and the Communitarian Trap", in Harvard Design Magazine ("Changing Cities"), Number 1, Winter/Spring 1997.

${ }_{18}$ Um exemplo bastante claro desta perspectiva, no âmbito da pintura, é o de Peter Fuller (1992), "Fine Arts" in B. Ford (ed.), Victorian Britain. CUP: 163-207. 
Poder-se-ia, assim, dizer que assistimos a uma nova Batalha dos Estilos no final do século Xx, numa troca de palavras que não perde em agressividade quando comparada com os seus antecessores oitocentistas. Os tradicionalistas/ classicistas falam de dogmatismo e da tirania dos modernistas - acusandoos de dominar todo o panorama da arquitectura, da Ordem às revistas da especialidade, da ensino universitário aos concursos públicos. Numa conceituada História das Artes britânicas publicada em 2000, Roy Strong, antigo director do Museu Victoria and Albert e da National Portrait Gallery, denuncia uma alegada subserviência política do modernismo aos interesses socialistas, a propósito de alguns dos empreendimentos lançados pelas autarquias no pós-guerra sob a batuta modernista: "Vast enterprises like the Parkhill and Hyde Park Estates in Sheffield (1955-65) bear witness to the triumph of Stalinist realism under the aegis of local Labour authorities" (Strong, 2000: 646). ${ }^{19}$ No mesmo tom, David Watkin, historiador e professor de História da Arquitectura da Universidade de Cambridge, compara os defensores do Modernismo aos Taliban, e queixa-se, num artigo recente, que "the survival of traditional and classical architecture was, and still is, ignored in architecture journals, rather as free thought was in Soviet Russia" (apud Parker, 2006).

Por seu lado, os "modernistas" criticam os seus adversários como praticantes do pastiche, pouco mais do que imitadores, recorrendo a fórmulas que tiveram o seu tempo - e não, como alguns defendem, como re-inventando o estilo. O RIBA defende-se das por vezes duras críticas que lhe são dirigidas argumentando que não tem qualquer posição ideológica contra o classicismo, tal como não tem uma postura de defesa aberta do modernismo, valorizando apenas a qualidade, inovação e criatividade dos projectos.

19 O empreendimento referido é um bairro social de enormes dimensões, uma experiência inovadora na Grã-Bretanha, em termos de construção social, não apenas pela dimensão mas também pela inspiração em Le Corbusier. O objectivo era o realojamento dos habitantes de um dos mais vastos e perigosos slums ainda existentes no país. Extremamente controverso no seu tempo como na actualidade, conseguiu evitar o destino da grande maioria das outras experiências deste tipo - a demolição - estando actualmente a ser alvo de uma interessante intervenção de restauro. 


\section{O futuro do passado}

O processo de implantação da arquitectura clássica na Grã-Bretanha ao longo de cinco séculos demonstra as ambiguidades subjacentes ao discurso identitário, centrado na identificação (inicialmente forçada) do classicismo paladiano com o modo de vida britânico, simbolizado na casa senhorial setecentista. Alguns dados recentes sobre a construção de residências particulares permitem uma visão das principais tendências na actualidade.

A sociedade britânica experimenta desde os anos 90 (e pelo menos até 2008) o maior surto de construção de mansões rurais de luxo dos últimos 150 anos, sobretudo nos condados do Sul de Inglaterra; na sua esmagadora maioria estas casas adoptam estilos de inspiração clássica - neojorgiano, neoeduardiano, até neobarroco (Sampson, 2002). Os multimilionários britânicos estão empenhados na construção de mansões de muitos milhões de libras, com opulentos parques ajardinados, que relembram, como comenta Sampson, o fulgor de outras épocas. Mais recentemente, são os multimilionários estrangeiros, nomeadamente russos, que se encontram entre os principais clientes dos arquitectos especialistas neste tipo de casa. Um dos arquitectos mais requisitados é justamente Robert Adam, autor da epígrafe desta comunicação.

O "clássico" continua também a ser apreciado e valorizado economicamente quando cristalizado na casa de cidade jorgiana que povoa as cidades de província, enquanto o "gótico", por seu lado, se multiplica em variantes para todas as bolsas, pelos sempre crescentes (e cada vez menos verdes) subúrbios britânicos. Em qualquer destas formas, a arquitectura dita tradicional está pujante, mantendo-se extremamente popular entre todas as classes da sociedade britânica, no que diz respeito à habitação familiar.

Um último dado permite uma ideia mais completa da situação. Tem sido frequentemente noticiado na imprensa britânica que a esmagadora maioria dos edifícios seleccionados para o prestigiante prémio Stirling, atribuído anualmente pelo RIBA, exclui os arquitectos "tradicionalistas" ou classicistas. Robert Adam alega também que o referido prémio "ignora a opinião popular" - 
a propósito de uma sondagem efectuada em 2009 sobre os gostos algo conservadores do público britânico em matéria de arquitectura (Booth, 2009).

Quando se completam quase 500 anos sobre a construção da Queen's House, em pleno século XXI, o debate sobre os caminhos da arquitectura britânica é indiscutivelmente interessante e profícuo. Mais do que isso: para além das polémicas, concursos como o que atribui o prémio Stirling demonstram que na Grã-Bretanha contemporânea o gosto pela tradição não impossibilita a ousadia e o espírito transgressivo e que a arquitectura britânica continua viva, porque criativa e inovadora.

\section{Bibliografia}

Arciszewska, Barbara (2004), "Classicism: Constructing the Paradigm in Britain and Europe" in Elisabeth McKellar and Barbara Arciszewska (eds.), Articulating British Classicism: New Approaches to Eighteenth-Century Architecture. Aldershot, England: Ashgate, 1-33.

Booth, Robert (2009), "Sterling Architecture Prize 'ignores public" in The Guardian, 17 October. http://www.guardian.co.uk/artanddesign/2009/oct/17/stirling-architecture-prize-riba-robert-adam.

Curl, James Stevens (2006), The Oxford Dictionary of Architecture and Landscape Architecture. Oxford: OUP.

Gomme, Andor (1992), "Architecture" in F. Ford (ed), Seventeenth Century Britain. Cambridge: CUP, 53-103.

Kruft, Hanno-Walter (1994), A History of Architectural Theory: from Vitruvius to the Present. New York and London: Princeton University Press and Zwemmer.

Lubbock, Jules (1995), The Tyranny of Taste. The Politics of Architecture and Design in Britain, 1550-1960. New Haven and London: Yale University Press.

Parker, Peter (2006), "The man who re-invented classicism", Daily Telegraph, 3 June: http:// www.telegraph.co.uk/culture/books/3652886/The-man-who-re-invented-classicism.html.

Ruskin, John (1853), The Stones of Venice, vol III. London: George Allen, 1906.

Sampson, Anthony (2002), "The New Edwardians", in The Observer, July 14: http://www. guardian.co.uk/theobserver/2002/jul/14/focus.news.

Strong, Roy (2000), The Spirit of Britain: A Narrative History of the Arts. London: Pimlico.

Summerson, John (1991), The Classical Language of Architecture. London: Thames and Hudson, (1 $1^{\mathrm{a}}$ edição, 1963).

Whiteley, Nigel (1992), "Falsehood in a Ciceronian dialect'?: The 'Ruskinian' Tradition, Modernism, and the Rise of the Classical Tradition in Contemporary Architecture" in Michael Wheeler and Nigel Whiteley (eds.), Ruskin, Tradition and Architecture. Manchester and New York: Manchester University Press, 179-211. 


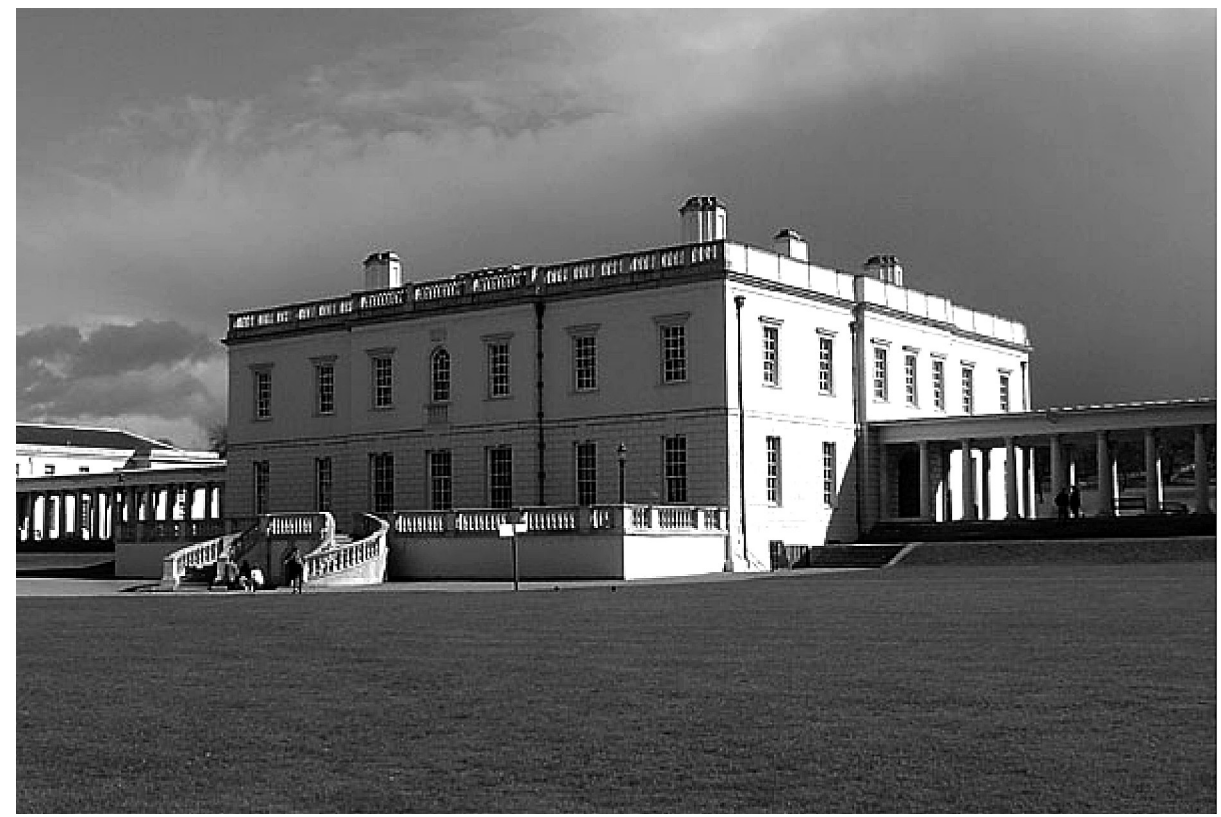

Fig. 1: Inigo Jones, Queen's House, 1619

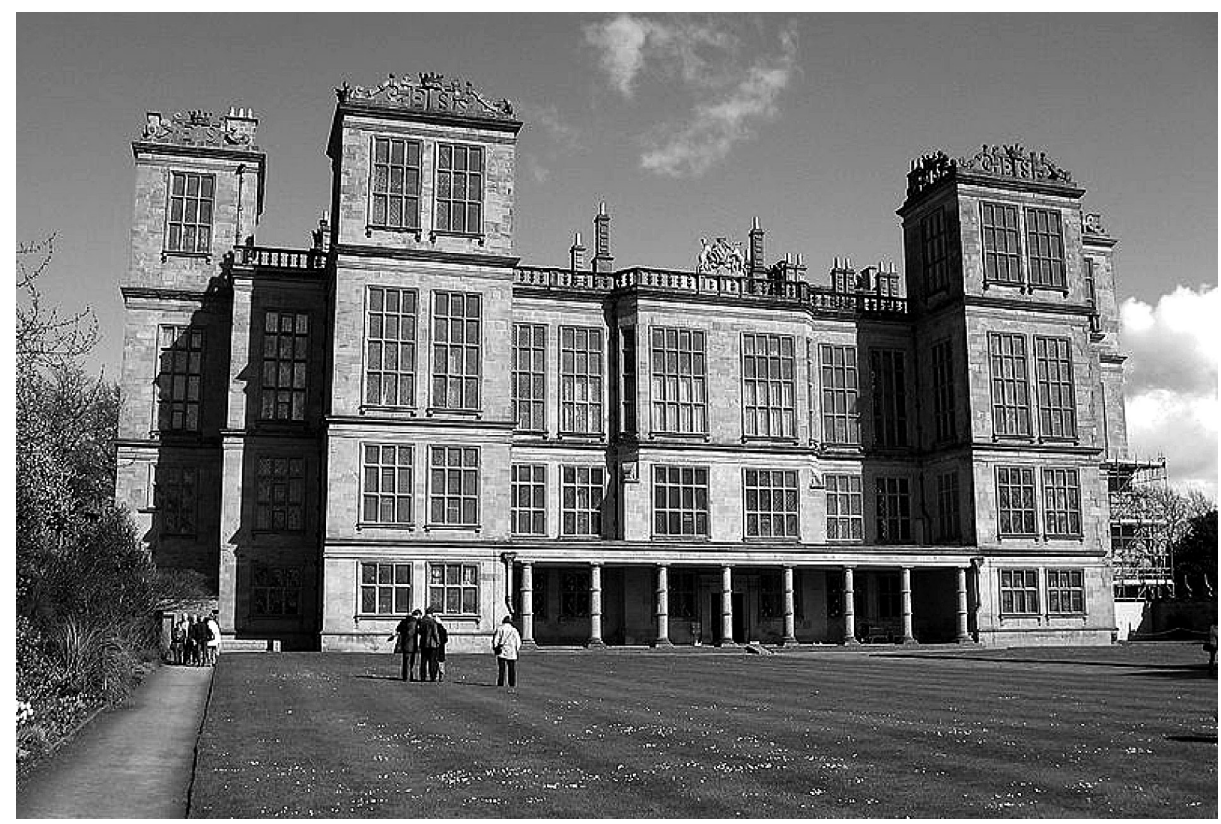

Fig. 2: Robert Smythe, Hardwick Hall, 1591 


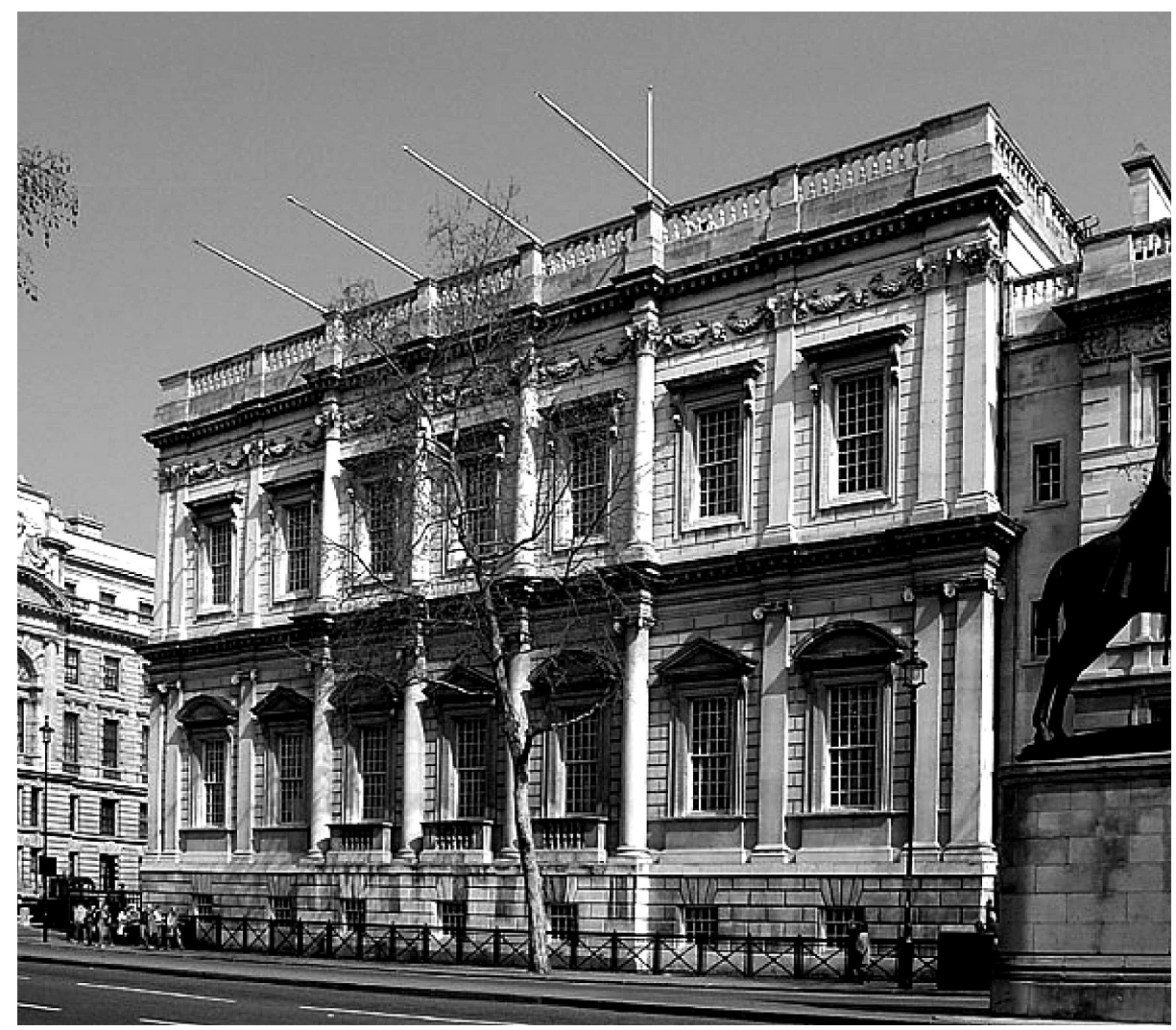

Fig. 3: Inigo Jones, Banqueting House, 1622 


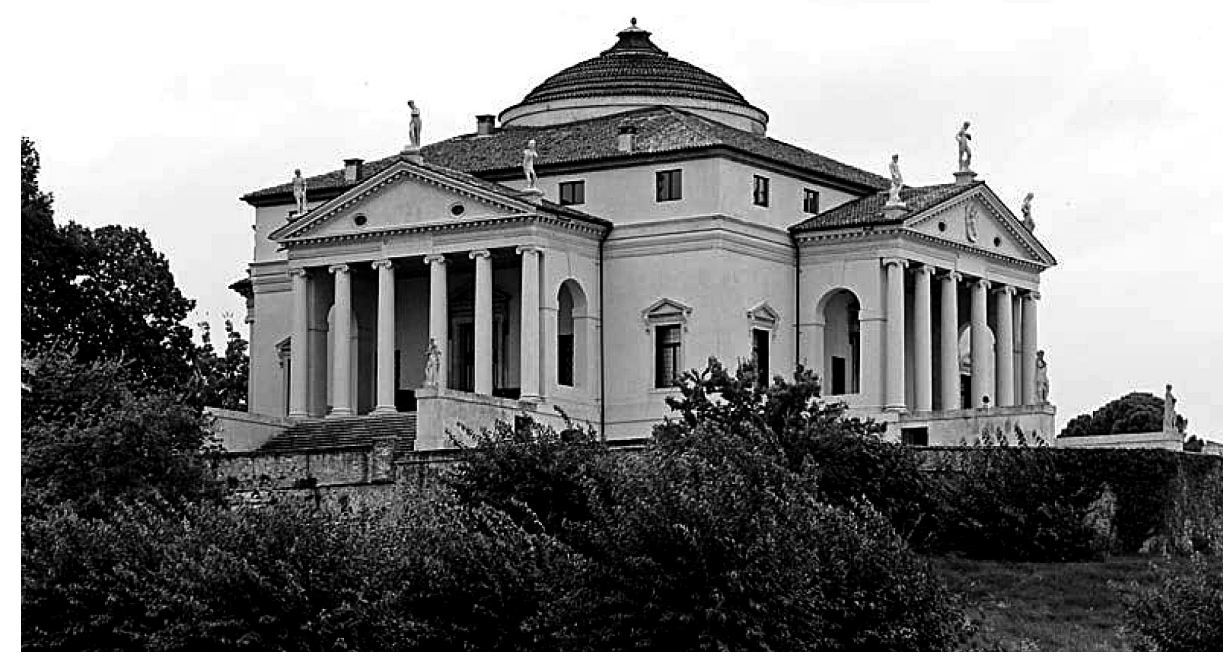

Fig. 4: Andrea Palladio, La Rotonda, 1591

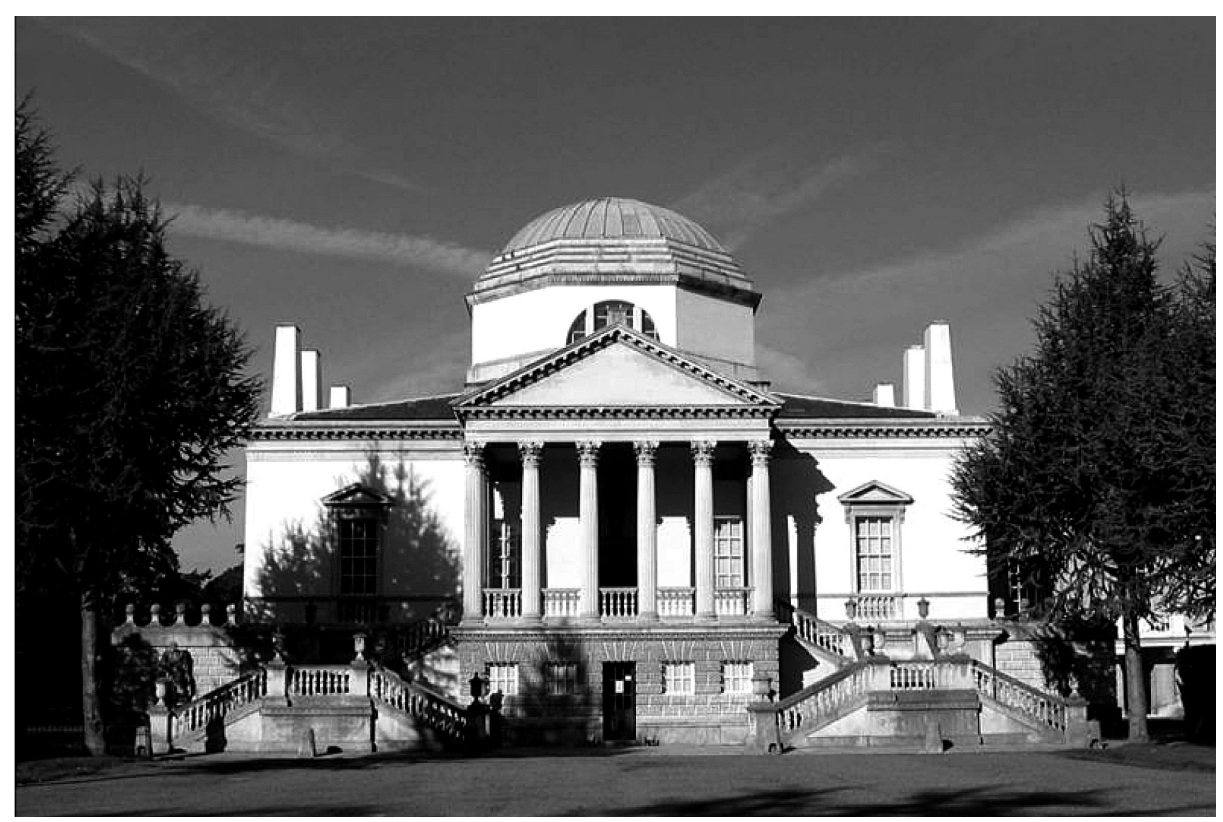

Fig. 5: Lord Burlington e William Kent, Chiswick House, 1729 


\section{Série}

\section{Documentos}

Imprensa da Universidade de Coimbra

Coimbra University Press

2011

- $\mathrm{U}$

C • 